Artvin Çoruh Üniversitesi

Orman Fakültesi Dergisi

ISSN:2146-1880, e-ISSN: 2146-698X

Yıl: 2021, Cilt: 22, Sayı:2, Sayfa: 300-305

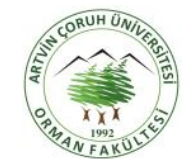

ofd.artvin.edu.tr
Artvin Coruh University

Journal of Forestry Faculty

ISSN:2146-1880, e-ISSN: 2146-698X

Year: 2021, Vol: 22, Issue:2, Pages: 300-305

\title{
Orman ürünleri sanayi sektöründe gri ilişkisel analiz yöntemiyle performans değerlendirme
}

\section{Evaluation of performance in the forest products industry sector with the grey relational analysis method}

\section{Kadri Cemil AKYÜZ}

Karadeniz Teknik Üniversitesi, Orman Fakültesi, Orman Endüstri Mühendisliği Bölümü, Trabzon

Eser Bilgisi / Article Info

Araştırma makalesi / Research article

DOI: 10.17474/artvinofd.992174

Sorumlu yazar / Corresponding author

Kadri Cemil AKYÜZ

e-mail: akyuz@ktu.edu.tr

Geliş tarihi / Received

07.09.2021

Düzeltme tarihi / Received in revised form

09.10.2021

Kabul Tarihi / Accepted

15.10.2021

Elektronik erişim / Online available

18.11.2021

Anahtar kelimeler:

Orman ürünleri sanayi

Gri ilişkisel analiz

Finansal oranlar

\section{Keywords:}

Forest products industry

Grey relational analysis

Financial ratios

\begin{abstract}
Özet
Günlük yaşantımızda ve gelecekle ilgili planlamalarımızda birçok faktör karar verme sürecini etkileyebilmekte ve en iyisini seçme endişesi önemli bir konu olarak karşımızda yer almaktadır. Finansal alanda yapılacak yatırımlarda ve alınacak olan kararlarda yapılacak hatalar kıt olan sermaye ve zaman faktörünün geri dönüşü olmayacak biçimde zarar görmesine neden olacaktır. Bu nedenle karar verilirken çok boyutlu ve alternatiflerin birlikte düşünülmesini gerektirecek yöntemlerin kullanılması gerekmektedir. Gri ilişkisel analiz yöntemi karar vermemize yardımcı olacak olan verilerin yetersizliği ya da kesinliğinin olmadığı durumlarda sıralama yapma ve karar konusunda derecelendirme yapabilme bakımından önemli ve kullanışlı çok boyutlu karar verme tekniği niteliğindedir. Bu çalışmamızda finansal yatırım konusunda Orman Ürünleri Sanayi sektörünü tercih etmek isteyen yatırımcılara firma seçiminde yardımcı olunması hedeflenmiş ve firmaların finansal performansları gri ilişkisel analiz tekniğiyle değerlendirilmiştir. Borsa İstanbul bünyesinde faaliyet gösteren beş adet firmanın analiz kapsamında yer aldığı çalışma 2016-2020 yılları dikkate alınarak gerçekleştirilmiştir. Çalışma sonucunda firmalar finansal oranlar bakımından sıralanmış ve yatırımcılara farklı bakış açısı sağlanmıştır.
\end{abstract}

\begin{abstract}
Many factors can affect the decision-making process in our daily life and in our plans for the future, and the concern of choosing the best is an important issue. Mistakes to be made in the investments to be made and the decisions to be made in the financial field will cause the scarce capital and time factor to be irreversibly damaged. For this reason, it is necessary to use multidimensional methods that require consideration of alternatives together while making a decision. The grey relational analysis method is an important and useful multidimensional decision-making technique in terms of ranking and grading the decision in cases where the data that will help us make decisions are insufficient or uncertain. In this study, it is aimed to help investors who want to choose the Forest Products Industry sector for financial investment in the selection of companies, and the financial performances of the companies are evaluated with the grey relational analysis technique. The study, which included five companies operating within Borsa Istanbul within the scope of the analysis, was carried out considering the years 2016-2020. As a result of the study, the companies were ranked in terms of financial ratios and different perspectives were provided to the investors.
\end{abstract}

\section{Giriş}

Birbiri ile çelişen, bir çok farklı faktörün değerlendirilmesini gerekli kılan ve karar sonucunun uzun süreli etkileri olan konularda, çok boyutlu karar verme teknikleri (ÇKKV)karar vericilere alternatifler arasında optimum çözümü veren özelliklere sahiptir. ÇKKV karar vericilere kolay ve etkin karar verme imkânı sağlayan alternatif karar noktaları hakkında performans bakımından sıralama yapabilen ve etkinlik ölçümünde kullanılan teknikler grubu olarak bilinmektedir (Meydan ve ark. 2016). ÇKKV yöntemleri arasında yer alan ve karmaşık formül ve problemlerin gerekli olmadığı bir çözüm tekniğine sahip olan Gri ilişkisel Analiz (GiA) üretim araçları, personel temini, tedarikçi seçimi, kuruluş yeri, optimizasyon ve bir çok konuda karar vericilere destek veren özelliklere sahip bir ÇKKV tekniğidir (Lin ve ark. 2002; Peker ve Baki 2011; Ayrıçay ve ark. 2013; Bektaş ve Tuna 2013; Tayyar ve ark. 2014; iç ve ark. 2015; Meydan ve ark. 2016; Akyüz ve ark. 2017; Kökçam ve ark. 2018; Akyüz ve ark. 2019).

Karar verme süreçlerinde kritik öneme sahip olan finansal performans değerlendirmesi, farklı finansal oran ve kalemlerin değerlendirilme sürecine alınma zorunluluğu ve büyük ölçüde bu oran ve kalemlerin birbirleriyle 
doğrudan bağlantılarının olmayışları nedeni ile zor ve karışık uygulamaları gerektirmektedir. Bu gibi durumlarda dikkat çekici nitelikte alternatif çözüm imkânı sunan GíA yöntemi başarı sıralamasında tercih edilen yöntemler arasındadır. Çalışmamızda hisse senetleri Borsa İstanbul'da (BiST) işlem gören Orman Ürünleri ve Mobilya Sanayi alanında yer alan firmaların finansal performanslarının GiA yöntemi ile belirlenmesi ve karşılaştırılması amaçlanmıştır. Finansal performans amacıyla firmaların 2016-2020 yıllarında yayınladıkları finansal tablolar kullanılmış ve belirlenen 12 farklı oran hesaplanarak elde edilen 5 yıllık ortalama değerler analize tabi tutulmuştur.

Belirsiz olan gelecek için bugünkü kaynaklarımızı kullanmak bir anlamda bugünkü konfor ve rahatımızdan vazgeçmek anlamını taşımaktadır. Dolayıyla bu alanda verilecek olan finansal kararlar birçok kesimi etkileyecek nitelikte önemlidir. GíA yöntemini kullanarak yapılan finansal tercih ve seçim tabanlı çalışmalarda; Feng ve Wang (2000), finansal oranlar yardımıyla Tayvan'da faaliyet gösteren hava yolu şirketlerinin finansal performanslarını değerlendirmiştir. Değerlendirmede Gri ilişskisel Analiz ve TOPSIS yöntemlerini ortak kullanmıştır. Çin çelik sanayinde yer alan firmaların finansal yatırım yapılabilirliği hakkında değerlendirmelerde bulunan Li ve Arkadaşları (2010), GíA yöntemi yardımıyla yatırımcılara yön çizmiştir. BIST'te işlem gören çimento firmalarını GiA yöntemi yardımıyla finansal performans açısından değerlendiren Güleç ve Özkan (2018), firmaların sıralamasını yapmıştır. Şengül ve Ece (2018), BiST 100'de işlem gören firmaların 2005-2017 yılları arasındaki finansal tablolarından elde etmiş oldukları finansal oranları GiA yöntemini kullanarak değerlendirmiş ve firmaları hisse senedi getirisi açısından sıralamışlardır. Gündoğdu (2018), Türkiye'de faaliyet gösteren katılım bankalarının finansal performanslarını GiA yöntemi ile incelemiş ve bankalar arasında sıralamalar yapmıştır. Kur dalgalanmalarının firmaların finansal yapı ve getirilerinde nasıl etkiler oluşturduğunun belirlenmesi amacıyla yapılan çalışmada Baş (2019), GíA yöntemini kullanmış ve firmaları finansal performans açısından sıralamıştır. Yıldırım ve arkadaşları (2021), Borsa İstanbul'da (BIST) Demir Çelik sanayi alanında işlem gören firmaların finansal performanslarının GiA yöntemi yardımıyla değerlendirmiş ve firmaları başarı açısından sıralamıştır. Ülkemizde faaliyet gösteren üç adet sigorta şirketinin finansal performans analizini finansal oranlar yardımıyla inceleyen Peker ve Baki (2011), şirketleri başarı bakımından sıralamıştır. Uygurtürk ve Korkmaz (2012), BIST'te işlem gören metal ana sanayi firmalarına yönelik finansal tablo verilerinden elde etmiş olduğu finansal oranlar yardımıyla yapmış olduğu analizde firmaları GiA yöntemi yardımıyla başarı açısından sıralamıştır.

Çizelge 1. Finansal Oranlar- Formül ve Referans

\begin{tabular}{lll}
\hline Oranlar & Formül & Referans \\
\hline Likidite Oranları & & MAK \\
Cari Oran (L1) & Dönen Varlık / Kısa Süreli Borçlar & MAK \\
Asit-Test Oranı (L2) & Dönen Varlıklar-Stoklar / Kısa Süreli Borçlar & MAK \\
Nakit Oranı (L3) & Hazır Değerler /Kısa Süreli Borçlar & MiN \\
Mali Yapı Oranları & Toplam Borç /Öz Sermaye & MiN \\
Toplam Borç / Öz Sermaye (M1) & Toplam Varlık /Öz Sermaye & MiN \\
Toplam Varlık / Öz Sermaye (M2) & Toplam Yabancı Kaynak /Toplam Aktif & MiN \\
Yabancı Kaynak / Toplam Aktif (M3) & Kısa Vadeli Borç /Toplam Aktif & MiN \\
Kısa Vadeli Borç (KVB) / Toplam Aktif (M4) & Uzun Vadeli Borç/Toplam Aktif & \\
Uzun Vadeli Borç (UVB) / Toplam Aktif (M5) & & MAK \\
Faaliyet Oranları & Net Satışlar / Toplam Aktif & MAK \\
Aktif Devir Hızı (F1) & Net Satışlar / Ticari Alacaklar & MAK \\
Alacak Devir Hızı (F2) & Satışların Maliyeti / Ortalama Stok & \\
Stok Devir Hızı (F3) & & MAK \\
Karlılık Oranları & Vergi Sonrası Net Kar / Net Satışlar & MAK \\
VSNK / Net Satışlar (K2) & Vergi Sonrası Net Kar / Öz Kaynak \\
VSNK / Öz Kaynak(K3) & Vergi Sonrası Net Kar / Toplam Varlık & MAK \\
VSNK / Toplam Varlık (K4) & & \\
\hline
\end{tabular}




\section{MATERYAL VE YÖNTEM}

\section{Materyal}

Orman ürünleri sanayi alanında bulunan 5 firmanın 20162020 yılları arasında yayınlamış oldukları finansal tablolardan elde edilen veriler yardımıyla hesaplanan 14 farklı oran (Çizelge 1) analiz kapsamında değerlendirilmiştir.

Belirlenen finansal oranlardan likidite, faaliyet ve karlıık oranlarının en yüksek, mali yapı oranlarının ise en küçük olması istenmektedir (Akgüç 2011). Bu nedenle analiz sırasında referans alınan değerler bu ölçüt dikkate alınarak belirlenmiştir. Yapılan yıllık hesaplamalar sonrasında 5 yıllık ortalama değerler alınarak analiz amacıyla firmalara ait oran tablosu elde edilmiştir. Çalışma materyalimizi BIST'te işlem gören orman ürünleri sanayi sektöründeki 5 firma (Çizelge 2) oluşturmaktadır. Analiz sırasında ve sonuç bölümünde firmaların isimleri farklı algılara neden olmamak için gizlenmiştir.

Çizelge 2. Analiz Kapsamındaki Firmalar

\begin{tabular}{l}
\hline Firmalar \\
\hline Sumaş Suni Tahta ve Mobilya Sanayi A.Ş. \\
Orma Orman Ürünleri İntegre Sanayi ve Ticaret A.Ş. \\
Gentaş Dekoratif Yüzeyler Sanayi ve Ticaret A.Ş. \\
Yonga Mobilya Sanayi ve Ticaret A.Ş. \\
Doğtaş Kelebek Mobilya Sanayi ve Ticaret A.Ş.
\end{tabular}

\section{Yöntem}

Deng (1982) tarafından belirsizliklerin sayısallaştırılması amacıyla geliştirilen ve birçok farklı alanda farklı kriterlerin kullanımına olanak sağlayan GíA, analiz amacıyla kullanılacak olan verilerin yetersiz veya eksik olduğu durumlar için kullanım imkânı oluşturan çok boyutlu karar verme teknikleri içinde yer almaktadır (Kökçam ve ark. 2018). Yapısı gereği karmaşık formül ve aşamalardan oluşmayan GíA yöntemi sistem davranışları arasında ilişkiler kurarak model kurabilmektedir (Köse ve ark. 2011). Sistem bilgisinin yeterli olmadığı durumu tanımlamak amacıyla kullanılan "Gri" kavramı, karşılaştırma yapılacak diziler arasındaki ilişkiyi hesaplayabilmek ve gri ilişki derecesi olarak adlandırılan 0 ve 1 arasında bir değerle ifade edebilmeyi hedeflemektedir. Altı adımdan oluşan GiA yönteminde adımları aşağıda sıralandığı şekildedir (Zhaı ve ark. 2009).
1.Karar matrisinin oluşturulması ( $m$ alternatifler ve $n$ kriterler olmak üzere),

$\mathrm{X}=\left[\begin{array}{cccc}X_{1}(1) & X_{1}(2) & \cdots & X_{1}(n) \\ X_{2}(1) & X_{2}(2) & \cdots & X_{2}(n) \\ \vdots & \vdots & \ddots & \vdots \\ X_{m}(1) & X_{m}(2) & \cdots & X_{m}(n)\end{array}\right]$

2. Referans serisinin oluşturulması (alternatifler arasında referans serisine en yakın olan seriyi bulmanın amaçlandığı bu aşamada en küçük ya da en büyük değerler referans olarak alınabilir),

$X_{0}=\left(X_{0}(1), X_{0}(2), \ldots \ldots, X_{0}(j), \ldots \ldots \ldots \ldots, X_{0}(n)\right)$

3.Karşılaştırma serisinin oluşturulması-Verilerin normalize edilmesi (amaca göre en büyük, en küçük ve optimum durum için farklı formüller kullanılır);

$X_{i}=X_{i}(j)-\min X_{i}(j) / \operatorname{mak} X_{i}(j)-\min X_{i}(j)$ (amaç en büyük değerin elde edilmesi olduğunda)

$X_{i}=\operatorname{mak}_{i}(j)-X_{i}(j) / \operatorname{mak} X_{i}(j)-\min X_{i}(j) \quad(a m a c ̧$ en küçük değerin elde edilmesi olduğunda)

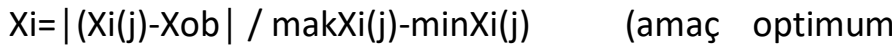
değerin elde edilmesi olduğunda)

4.Mutlak değer tablosunun oluşturulması (referans değerle sırada yer alan değer arasındaki farkın alınması işlemidir),

$\Delta \mathrm{Xi}(J)=\mid(\mathrm{Xi}(\mathrm{j})-\mathrm{Xob} \mid$

5.Farklı veri dizinlerine ait gri ilişkisel katsayı matrisinin hesaplanması (" $\gamma$ " ayırıcı katsayısı olup 0-1 arasında değişim göstermektedir. İşlemlerde 0,5 olarak alınması tavsiye edilir),

$\mathrm{K}(\mathrm{j})=(\Delta \mathrm{enk}+\gamma \Delta \mathrm{enb}) /(\Delta \mathrm{i}(\mathrm{j})+\gamma \Delta \mathrm{enb})$

$\Delta$ enk= Dizi içindeki en küçük değişim değeri

$\Delta$ enb= Dizi içindeki en büyük değişim değeri

6.ilişki matrisini oluşturmak için her fark veri seti için ilişki derecesinin hesaplanması (" $\mathrm{i}$ " gri ilişki derecesini 
gösterir. Çalışmamızda kullanılan oranların hepsinin eşit ağırlıkta olduğu kabul edilmiştir),

$\Gamma \mathrm{i}=\frac{1}{n} \sum_{j=1 \mathrm{~K}(\mathrm{~m})}^{n} \quad$ (Çalışmada kullanılan kriterlerinoranların eşit ağırlıkta olması durumunda kullanııı)

$\Gamma \mathrm{i}=\frac{1}{n} \sum_{j=1 K(m) w(m)}^{n} \quad$ (Çalışmada kullanılan kriterlerinoranların farklı ağırlıkta olması durumunda kullanılır)

\section{BULGULAR}

BIST bünyesinde orman ürünleri sanayi alanında faaliyet gösteren firmaların finansal performanslarının belirlenmesi amacıyla gerçekleştirilen çalışmanın ilk aşamasında 2016-20120 yılları kapsamında elde edilen 14 farklı orana ait ortalama değerler analiz amacıyla karar matrisi şeklinde Çizelge 3'te gösterilmektedir.

Çizelge 3. Orman Ürünleri Sanayi Firmalarının Finansal Oran Ortalamaları (2016-2020)

\begin{tabular}{llllll}
\hline Oranlar & $(\mathrm{A})$ & $(\mathrm{B})$ & $(\mathrm{C})$ & $(\mathrm{D})$ & $(\mathrm{E})$ \\
\hline L1 & 0.803 & 2.862 & 0.539 & 3.524 & 1.709 \\
L2 & 0.361 & 1.518 & 0.418 & 2.515 & 0.789 \\
L3 & 0.007 & 0.320 & 0.007 & 2.083 & 0.326 \\
M1 & -10.884 & 0.421 & 3.561 & 0.604 & 0.840 \\
M2 & -9.884 & 1.397 & 4.561 & 1.604 & 1.840 \\
M3 & 0.953 & 0.283 & 0.773 & 0.343 & 0.439 \\
M4 & 0.694 & 0.231 & 0.615 & 0.273 & 0.334 \\
M5 & 0.257 & 0.063 & 0.157 & 0.070 & 0.104 \\
F1 & 3.646 & 0.978 & 0.445 & 1.409 & 1.159 \\
F2 & 2.504 & 4.501 & 2.177 & 53.690 & 14.666 \\
F3 & 2.224 & 2.561 & 4.845 & 5.047 & 3.945 \\
K1 & -0.061 & 0.100 & -0.136 & 0.178 & 0.021 \\
K2 & 3.649 & 0.139 & -0.279 & 0.381 & 0.016 \\
K3 & 0.007 & 0.098 & -0.059 & 0.251 & 0.015 \\
\hline
\end{tabular}

Analizin ikinci aşaması veri seti yardımıyla referans serisi sütunü elde edilir. Bu aşamada finansal oranların istenilen niteliklerde olması dikkate alınarak en yüksek ya da en düşük değerler temel alınır. Referans değerlerinin yer aldığı veriler Çizelge 4'te gösterilmektedir. Çalışmada kullanılan oranların nitelikleri ve hedeflenen yönleri dikkate alınarak yapılan hesaplama sonucunda; özellikle kısa vadeli borç ödeme gücünün göstergesi sayılan ve yüksek olması istenilen likidite oranları bakımından $D$ firmasının referans alınacak niteliklerde olduğu görülmektedir. Finansal borç yükünün düşük olması istenen bir durum olması nedeniyle, mali yapı oranları bakımından en düşük değerli olan firmaların değerleri referans değeri olarak alınmaktadır. Referans değerleri incelendiğinde toplam borç ve toplam varlığın öz sermayeye oranı bakımından A firması, toplam yabancı kaynağın, kısa vadeli borcun ve uzun vadeli borcun toplam aktife oranı bakımından ise B firmasının referans alınması gerekmektedir. Yüksek olmaları istenilen faaliyet oranları bakımından; aktif devir hızı için A firması, alacak devir hızı ve stok devir hızı için ise $D$ firması referans alınmalıdır. Karlılık oranları bakımından ise VSNK/net satışlar ile VSNK/toplam varlık oranları bakımından D firması, VSNK/öz kaynaklar bakımından ise A firmasının referans alınması gerektiği görülmektedir.

\begin{tabular}{lllllll}
\multicolumn{6}{l}{ Çizelge 4. Karşılaştırma Matrisi } \\
\hline Oranlar & Refer & (A) & (B) & (C) & (D) & (E) \\
\hline L1 & 3.524 & 0.803 & 2.862 & 0.539 & 3.524 & 1.709 \\
L2 & 2.515 & 0.361 & 1.518 & 0.418 & 2.515 & 0.789 \\
L3 & 2.083 & 0.007 & 0.320 & 0.007 & 2.083 & 0.326 \\
M1 & -10.884 & -10.884 & 0.421 & 3.561 & 0.604 & 0.840 \\
M2 & -9.884 & -9.884 & 1.397 & 4.561 & 1.604 & 1.840 \\
M3 & 0.283 & 0.953 & 0.283 & 0.773 & 0.343 & 0.439 \\
M4 & 0.231 & 0.694 & 0.231 & 0.615 & 0.273 & 0.334 \\
M5 & 0.063 & 0.257 & 0.063 & 0.157 & 0.070 & 0.104 \\
F1 & 3.646 & 3.646 & 0.978 & 0.445 & 1.409 & 1.159 \\
F2 & 53.690 & 2.504 & 4.501 & 2.177 & 53.690 & 14.666 \\
F3 & 5.047 & 2.224 & 2.561 & 4.845 & 5.047 & 3.945 \\
K1 & 0.178 & -0.061 & 0.100 & -0.136 & 0.178 & 0.021 \\
K2 & 3.649 & 3.649 & 0.139 & -0.279 & 0.381 & 0.016 \\
K3 & 0.251 & 0.007 & 0.098 & -0.059 & 0.251 & 0.015 \\
\hline
\end{tabular}

Referans değerlerinin belirlenmesi sonrasında ortalama değerlerin normalize edilmesi aşamasına geçilmektedir. Bu aşamada daha önce tanımlanan ve yüksek ya da düşük olması isteğine bağlı olarak tanımlanan formüller kullanılmaktadır. Yüksek olması istenilen likidite, faaliyet ve karlılık oranları için (2) numaralı formül, düşük olması istenilen mali yapı oranları için ise (3) numaralı formül kullanılarak Çizelge 5 'te yer alan değerler elde edilmiştir.

\begin{tabular}{lllllll}
\multicolumn{6}{l}{ Çizelge 5. Normalize Matrisi } \\
\cline { 1 - 4 } Oranlar & Refer & (A) & (B) & (C) & (D) & (E) \\
\hline L1 & 1.000 & 0.088 & 0.778 & 0.000 & 1.000 & 0.392 \\
L2 & 1.000 & 0.000 & 0.537 & 0.026 & 1.000 & 0.143 \\
L3 & 1.000 & 0.000 & 0.150 & 0.004 & 1.000 & 0.153 \\
M1 & 1.000 & 1.000 & 0.217 & 0.000 & 0.204 & 0.188 \\
M2 & 1.000 & 1.000 & 0.219 & 0.000 & 0.204 & 0.188 \\
M3 & 1.000 & 0.000 & 1.000 & 0.268 & 0.910 & 0.767 \\
M4 & 1.000 & 0.000 & 1.000 & 0.170 & 0.909 & 0.777 \\
M5 & 1.000 & 0.000 & 1.000 & 0.515 & 0.963 & 0.788 \\
F1 & 1.000 & 1.000 & 0.166 & 0.000 & 0.301 & 0.223 \\
F2 & 1.000 & 0.006 & 0.045 & 0.000 & 1.000 & 0.242 \\
F3 & 1.000 & 0.000 & 0.119 & 0.928 & 1.000 & 0.609 \\
K1 & 1.000 & 0.627 & 0.751 & 0.000 & 1.000 & 0.500 \\
K2 & 1.000 & 1.000 & 0.106 & 0.000 & 0.168 & 0.075 \\
K3 & 1.000 & 0.212 & 0.506 & 0.000 & 1.000 & 0.238 \\
\hline
\end{tabular}

Normalize değerler matrisi elde edildikten sonra referans değerleri ile aralarında oluşan uzaklığın hesaplanması 
sonucunda oluşturulan ve Çizelge $6^{\prime}$ da görülen mutlak değerler tablosu elde edilmiştir.

Mutlak değerler tablosu hesaplanması sonrasında gri ilişkisel katsayısı matrisi hesaplanmıştır. Çalışmada kullanılan finansal oranların hepsinin eşit öneme sahip olduğu kabulü ile yapılan hesaplama sonucunda $(\gamma)$ gri ilişki katsayısı 0.5 olarak alınmıştır. (7) numaralı formül kullanılarak hesaplanan gri ilişki derecesi sonuçları Çizelge 7'de gösterilmektedir.

Çizelge 6. Mutlak Değerler Matrisi

\begin{tabular}{llllll}
\hline Oranlar & $(\mathrm{A})$ & $(\mathrm{B})$ & $(\mathrm{C})$ & $(\mathrm{D})$ & $(\mathrm{E})$ \\
\hline L1 & 0.912 & 0.222 & 1.000 & 0.000 & 0.608 \\
L2 & 1.000 & 0.463 & 0.974 & 0.000 & 0.857 \\
L3 & 1.000 & 0.850 & 0.996 & 0.000 & 0.847 \\
M1 & 0.000 & 0.783 & 1.000 & 0.796 & 0.812 \\
M2 & 0.000 & 0.781 & 1.000 & 0.796 & 0.812 \\
M3 & 1.000 & 0.000 & 0.732 & 0.090 & 0.233 \\
M4 & 1.000 & 0.000 & 0.830 & 0.091 & 0.223 \\
M5 & 1.000 & 0.000 & 0.485 & 0.037 & 0.212 \\
F1 & 0.000 & 0.834 & 1.000 & 0.699 & 0.777 \\
F2 & 0.994 & 0.955 & 1.000 & 0.000 & 0.758 \\
F3 & 1.000 & 0.881 & 0.072 & 0.000 & 0.391 \\
K1 & 0.373 & 0.249 & 1.000 & 0.000 & 0.500 \\
K2 & 0.000 & 0.894 & 1.000 & 0.832 & 0.925 \\
K3 & 0.788 & 0.494 & 1.000 & 0.000 & 0.762 \\
\hline
\end{tabular}

$L 1, L 2$ ve $L 3$ oranları düzeyinde $D$ firmasının tam etkin olduğu görülmektedir. M1 ve M2 oranları düzeyinde A firması M3, M4 ve M5 oranları düzeyinde ise B firmasının tam etkinliği görülmektedir. F1 oranında $A$ firması, F2 ve $F 3$ oranlarında ise $D$ firması tam etkindir. Karlılık oranları açısından yapılan hesaplama sonucunda ise $\mathrm{K} 1$ ve $\mathrm{K} 3$ oranlarında $D$ firması, $K 2$ oranında ise A firmasının tam etkin olduğu görülmektedir. A firması 4 oran düzeyinde, B firması 3 oran düzeyinde, $D$ firması ise 7 oran düzeyinde tam etkindir. Diğer firmalar hesaplama kapsamında yer alan oranlar düzeyinde etkinlik sağlayamamışlardır.

\begin{tabular}{llllll}
\multicolumn{6}{l}{ Çizelge 7. Gri İlişkisel Katsayı Matris } \\
\hline Oranlar & (A) & (B) & (C) & (D) & (E) \\
\hline L1 & 0.354 & 0.692 & 0.333 & 1.000 & 0.451 \\
L2 & 0.333 & 0.519 & 0.339 & 1.000 & 0.368 \\
L3 & 0.333 & 0.370 & 0.334 & 1.000 & 0.371 \\
M1 & 1.000 & 0.389 & 0.333 & 0.385 & 0.881 \\
M2 & 1.000 & 0.390 & 0.333 & 0.385 & 0.381 \\
M3 & 0.333 & 1.000 & 0.405 & 0.847 & 0.682 \\
M4 & 0.333 & 1.000 & 0.375 & 0.846 & 0.691 \\
M5 & 0.333 & 1.000 & 0.507 & 0.931 & 0.702 \\
F1 & 1.000 & 0.374 & 0.333 & 0.417 & 0.391 \\
F2 & 0.334 & 0.343 & 0.333 & 1.000 & 0.397 \\
F3 & 0.333 & 0.362 & 0.874 & 1.000 & 0.561 \\
K1 & 0.572 & 0.667 & 0.333 & 1.000 & 0.500 \\
K2 & 1.000 & 0.370 & 0.333 & 0.375 & 0.350 \\
K3 & 0.388 & 0.530 & 0.333 & 1.000 & 0.396 \\
\hline
\end{tabular}

Gri ilişki katsayı matrisi sonrasında yapılan hesaplamalarla elde edilen gri ilişkisel analiz sonuçları Çizelge $8^{\prime}$ de gösterilmektedir.

Çizelge 8. Gri İlişkisel Analiz Sonuçları

\begin{tabular}{|c|c|c|c|c|c|c|c|c|c|c|}
\hline Firmalar & $\begin{array}{l}\text { Likidite } \\
\% 51.98\end{array}$ & & $\begin{array}{l}\text { Mali Yapı } \\
\% 61.85\end{array}$ & & $\begin{array}{l}\text { Faaliyet } \\
\% 53.67\end{array}$ & & $\begin{array}{l}\text { Karlılık } \\
\% 54.32\end{array}$ & & İlişki & Genel \\
\hline$A$ & $\% 34.00$ & 4 & $\% 59.98$ & 4 & $\% 55.56$ & 2 & $\% 65.33$ & 2 & $\% 53.71$ & 3 \\
\hline B & $\% 52.70$ & 2 & $\% 75.58$ & 1 & $\% 35.96$ & 5 & $\% 52.23$ & 3 & $\% 54.11$ & 2 \\
\hline $\mathrm{C}$ & \%33.53 & 5 & \%39.06 & 5 & \%51.33 & 3 & \%33.33 & 5 & \%39.31 & 5 \\
\hline$D$ & $\% 100$ & 1 & $\% 67.88$ & 2 & $\% 80.56$ & 1 & \%79.16 & 1 & $\% 81.90$ & 1 \\
\hline $\mathrm{E}$ & \%39.66 & 3 & $\% 66.74$ & 3 & $\% 44.97$ & 4 & $\% 41.53$ & 4 & $\% 48.22$ & 4 \\
\hline
\end{tabular}

Oran grupları düzeyinde mali yapı oranlarının önem düzeyinin diğer oran grupları üzerinde değere sahip olması firmalar düzeyinde en önemli finansal göstergenin mali yapı oranları olduğunu belgelemektedir. Mali yapı oranlarının etkinlik değerleri \%75.58 ile \%39.06 arasında değişim göstermektedir. Mali yapı oranlarını \%54.32 ile karlılık oranları izlemektedir. Faaliyet oranları 3. sırada ve likidite oranları ise 4. önemsel düzeyde bulunmaktadır.

Firmalar düzeyinde yapılan analiz sonucunda genel sıralamada $D$ firmasının etkinlik bakımından ilk sırada yer aldığı, bu firmayı B ve A firmalarının izlediği görülmektedir. Genel ilişki düzeyi bakımından etkinlik düzeylerinin \%81.90 ile \%39.31 arasında değişim gösterdiği görülmektedir. D firmasının özellikle nakit dengesini oluşturmadaki başarısı ve borç yapılanmasındaki düşük düzey firmanın risk puanının azalmasını sağlamış ve ilk sırada yer almasında etkin olmuştur. Ayrıca varlıklarının paraya dönüşümü ve stok döngüsündeki başarısı ilk sırada olmasını perçinlemiştir. ikinci sırada yer alan B firması ise incelenen yıllar kapsamında sahip olduğu karlılık oranlarında sağlamış olduğu istikrarlı artış ile ikinci sırada yer almıştır. Özellikle öz kaynak karlılığında yıllar ortalamasında sağlamış 
olduğu yüksek değer A firmasının üçüncü sırada yer almasında etkin olmuştur. Gri ilişkisel analiz sonuçları incelendiğinde özellikle likidite ile mali yapı oranlarının ve faaliyet ile karlılık oranlarının birlikte hareket ettikleri gözlemlenmektedir.

\section{SONUÇ VE ÖNERILER}

Orman ürünleri sanayi sektöründe yer alan firmaların gri ilişkisel analiz yöntemi kullanılarak finansal oranları yardımıyla başarı düzeylerinin belirlenmesinin amaçlandığı çalışma sonucunda gerek oran grupları düzeyinde ve gerekse firmalar bütününde önem ve başarı sıralamaları yapılmıştır. Yapılan değerlendirme sonucunda oransal düzeyde orman ürünleri sanayi firmaları açısından mali yapı oranlarının başarı sıralamasında ilk sırada, likidite oranlarının ise son sırada yer aldığı görülmektedir. Mali dengesini düzgün bir biçimde oluşturma becerisine sahip olan firmaların likidite dengesinde sorun yaşamadıkları ve başarılı olma konusunda ön sıralarda yer aldıkları görülmektedir. Borç ve kaynak yapısı bakımından dış kaynağa ve dolayısıyla yüksek faiz ödeme zorunluluğuna katlanmak zorunda kalan firmalar başarısız olmaktadır. Bu nedenle firmaların kendi öz kaynakları ile faaliyetlerini sürdürme eğilimlerinde olmaları özellikle dış kaynak bulmada sıkıntı yaşanan dönemler kapsamında hayati öneme sahiptir. Firmaların faaliyet alanları ya da farklı yatırım ortamlarına yönelmeleri, sağlam kaynak yapısı sayesinde başarı ile sonuçlanabilecektir. Özellikle riskli ve finansal açıdan kaynak kısıtının bulunduğu dönemlerde firmaların büyüme ile ilgili kararlarını dikkatli bir biçimde almaları başarı açısından gerekli unsurların başında gelmektedir.

\section{KAYNAKLAR}

Akgüç Ö (2011) Mali Tablolar Analizi. Genişletilmiş 14. Baskı, Avcıol Basım Yayın, İstanbul.

Akyüz KC, Akyüz İ, Yıldırım I, Ersen N (2019) Borsa İstanbul da BasımYayın Sanayi Grubunda Yer Alan Şirketlerin Performanslarının Gri illişkisel Analiz Yöntemi İle Değerlendirilmesi. Türkiye Sosyal Araştırmalar Dergisi 23(1): 141-152.

Akyüz KC, Ersen N, Akyüz i (2017) Borsa İstanbul da Faaliyet Gösteren Kağıt ve Kağıt Ürünleri Sanayi Sektörü Firmalarının Performanslarının Gri İlişkisel Analiz Yöntemiyle Değerlendirilmesi. The Journal of Academic Social Science 51: 139-151.

Ayrıçay Y, Özçalııı M. Kaya A Ak (2013) Gri İlişkisel Analizin Finansal Kıyaslama Aracı Olarak Kullanılması: iMKB-30 Endeksindeki
Finansal Olmayan Firmalar Üzerine Bir Uygulama. Kahramanmaraş Sütçü İmam Üniversitesi Sosyal Bilimler Dergisi 10(1): 219-238.

Baş M (2019) Gri ílişkisel Analiz ile Finansal Performans: Bist Uygulaması. Journal of Social and Humanities Sciences Research 6(42): 2780-2789.

Bektaş H, Tuna K (2013) Borsa İstanbul Gelişen İşletmeler Piyasasında İşlem Gören Firmaların Gri İlişkisel Analiz İle Performans Ölçümü. Çankırı Karatekin Üniversitesi İktisadi ve İdari Bilimler Fakültesi Dergisi 3(2): 185-198.

Deng JL (1982) Control Problems of Grey Systems. Systems and Control Letters. 1(5): 288-294.

Feng CM, Wang RT (2000) Performance Evaluation For Airlines Including the Consideration of Financial Ratios. Journal of Air Transport Management 6(3): 133-142.

Güleç ÖF, Özkan A (2018) Gri illişkisel Analiz Yöntemi ile Finansal Performansın Değerlendirilmesi: BIST Çimento Şirketleri Üzerine Bir Araştırma. Muhasebe ve Denetime Bakış Dergisi 54 (4): 77- 96.

Gündoğdu A (2018) Türkiye'de Katılım Bankalarının Performansının Gri İlişki Analizi İle Ölçülmesi. Uluslararası İktisadi ve İdari İncelemeler Dergisi 17. Uік Özel Sayısı: 201-214.

Köse E, Temiz I, Erol S (2011) Grey System Approach for Economic order Quantitiy Models Under Uncertainty. Journal of Grey System 23(1): 71-82.

Kökçam AH, Uygun Ö, Kılıçaslan E (2018) Gri illişkisel Analiz Yöntemiyle Optimum Lastik Seçimi. Zeki Sistemler Teori ve Uygulamalar Dergisi 1(1): 31-35.

Lin CL, Lin JL, Ko TC (2002) Optimisation of the EDM Process Based on the Orthogonal Array with Fuzzy Logic and Grey Relational Analysis Method. The International Journal of Advanced Manufacturing Techology 19(4): 271-277.

Li HY, Zhang C, Zhao D (2010) Stock Investment Value Analysis Model Based on AHP and Gray Relational Degree. Management Science and Engineering 4(4): 1-6.

Meydan C, Yıldırım B, Senger Ö (2016) BIST'te İşlem Gören Gıda İşletmelerinin Finansal Performanslarının Gri ilişsisel Analiz Yöntemi Kullanılarak Değerlendirilmesi. Muhasebe ve Finans Dergisi Ocak: 147-167.

iç YT, Tekin M, Pamukoğlu FZ, Yıldırım SE (2015) Kurumsal Firmalar İçin Bir Finansal Performans Karşılaştırma Modelinin Geliştirilmesi. Gazi Üniversitesi Mühendislik Fakültesi Dergisi 30(1): 71-85.

Peker I, Baki B (2011) Gri ilişkisel Analiz Yöntemiyle Türk Sigortacılık Sektöründe Performans Ölçümü. Uluslararası İktisadi ve İdari Incelemeler Dergisi 7: 1-18.

Şengül Ü, Ece N (2018) Gri ílişkisel Analiz Yöntemi ile Finansal Performans Değerlendirilmesi: BIST 100 Üzerine Bir Araştırma. Journal of Awareness 3(5): 865-880.

Tayyar N, Akcanlı F, Genç E, Erem I (2014) BIST' e Kayıtlı Bilişim ve Teknoloji Alanında Faaliyet Gösteren İşletmelerin Finansal Performanslarının Analitik Hiyerarşi Prosesi (AHP) ve Gri İlişkisel Analiz (GIA) Yöntemiyle Değerlendirilmesi. Muhasebe ve Finansman Dergisi Ocak: 19-40.

Uygurtürk H, Korkmaz T (2012) Finansal Performansın TOPSIS Çok Kriterli Karar Verme Yöntemi ile Belirlenmesi: Ana Metal Sanayi İşletmeleri Üzerine Bir Uygulama. Eskişehir Osmangazi Üniversitesi Iktisadi ve İdari Bilimler Dergisi 7(2): 95-115.

Yıldırım M, Bal K, Doğan M (2021) Gri İlişkisel Analiz Yöntemi ile Finansal Performans Analizi: BIST' te İşlem Gören Demir Çelik Şirketleri Üzerine Bir Uygulama. Muhasebe Bilim Dünyası Dergisi 23(1): 122-143.

Zhal LY, Khoo LP, Zhong ZW (2009) Design Concept Evaluation in Product Devolopment Using Rough Sets and Grey Relation Analysis. Expert System with Applications 36: 7072-7079. 